\title{
The College P.E. Teaching Evaluation System Based on Grey- TOPSIS method and Computer Simulation
}

\author{
Shengtao $\mathrm{Wu}$ \\ Yangtze normal college \\ lanlan8528@126.com
}

\begin{abstract}
The physical education curriculum is always outdoor and the exam is not in written form. However, there is few evaluation system can evaluate the P.E. teaching effect. Thereby, we try to establish an evaluation system to evaluate the college physical education curriculum comprehensively. As we all know, the assessment of college physical education curriculum is a multi-attribute assessment problem. The traditional TOPSIS Method is only to evaluate the problem whose attributes belong to precise type. But, we also meen the situation that the attribute value is interval value. In this paper, we propose an improved TOPSIS method (Grey-TOPSIS) to solve above problem. This method can evaluate the problem whose attributes belong to interval type. Then, we applo this method to establish the college physical education curriculum evaluation system. The numerical analysis shows that this method can solve the problem whose attributes belong to precise type effectively and feasibly. And the college P.E. evaluation system can evaluatethe teaching effect accurately.
\end{abstract}

Keywords: Grey-TOPSIS, college P.E. teaching evaluation system, multi-attribute, computer simulation

\section{Introduction}

The school physical education evaluation is an important means to achieve the teaching goal and promote the development of the school sports. It belongs to the education evaluation. In the compehensive promorion of the quality education, the school physical education assessment plays a significantrole in the value orientation and management supervision. The college physical education assessment is a crucial part of the ordinary university sports work. The comprehensive evaluation of the ordinary university sports belongs to the social engineering management system. Because it is a complex system, we must consider a number of related factors when make any decision on the complex social engineering management system. This is called the multi-attribute evaluation problem.

However, in current network construction of colleges and universities, there are not any effectie college P.E teaching evaluation systems. We cannot evaluate the college sports effectively. And we cannot evaluate and order the teaching level of each university. Therefore, it is extremely essential and urgent to establish the university physical education teaching evaluation system.

At present, some scholars begin to evaluate the college physical education in China. Zhang Xiaodong assessed the ordinary college sports by using the fuzzy mathematics [1]. Firstly, he determined the evaluated content of the ordinary college sports. Then he established the index system of each contents and the comprehensive evaluation mathematical model. At last, he used the instances to discuss the ordinary college sport evaluation the mathematically. Xu Mingxin, Chuan Gaobin and Ju Chuanjin studied the application theory and the application 
method of the meta-evaluation [2]. The meta-evaluation is an evaluation method to evaluate itself. They thought the school sports assessment should contain the meta-evaluation. The focus, application strategy, and application method is an important part for the metaevaluation. The meta-evaluation has a significant application value in evaluating the technological quality, correcting the deviation, enhancing the value and strengthening the school sports evaluation functions. Li Dong explored the college education evaluation function [3]. He believed that the college physical education evaluation is a purposeful and organized cognitive activity. The strong purpose and the well organization often make people focus on the positive function and neglect the negative influence. However, the positive influence and the negative influence must always affect the college physical education evaluation process no matter whether we pay attention or not.

The Technique for Order of Preference by Similarity to Ideal Solution (TOPSIS), proposed by Hwang and Yoon [4], is one of the most used methods to support MCDM (Malti-criteria Decision Making). The main idea of TOPSIS is that the solution should be as far as possible from the worst possible solution and as close as possible from the best possib e solution. TOPSIS simultaneously considers information about the positive and negative ideal solutions. Moreover, the calculation is simple, making TOPSIS widely used in multi-attribute evaluation. In applications, depending on the characteristics of the survey data, the TOPSIS method modified using fuzzy theory is capable of solving many practical evaluation issues. Examples include performance evaluation [5], customer evaluation [6], energy plans [7], and business competitiveness evaluation [8].

TOPSIS is quite simple and intuitive, presenting a satisfactory performance in many applications. Some scholars made a broad survey about the TOPSIS method [9]. Despite the importance of the TOPSIS method, there are sone other difficult in the MCDM problems [10], human thinking is not completey rational presenting strong bias in some situations. In order to consider the human bias in the MCDM methods, Gomes and Lima proposed the TODIM (an acronym in Portuguese of Interaetive and Multi-criteria Decision Making) method, one of the first MCDM methods based on the Prospect Theory [11]. In the standard formulations, the TOPSIS and TODIM methods deal with crisp numbers only. This is a serious drawback. Crisp numbers are very precise information and sometimes this desired accuracy is not possible to achieve. Several types of information have been considered in the MCDM mode1s. For example, there are many TOPSIS adaptations to deal with probability distribution information [12], Uzzy information [13-15]), intuitionistic fuzzy information [16] and so on. On the other hand, the TODIM method was extended first to deal with fuzzy numbers [17], intuition istic fuzzy information [18] and intuitionistic fuzzy information in a random environment [19]. Also, a hybrid TODIM was proposed which deals with crisp numbers and fuzzy numbers at the same time [20].

The traditional TOPSIS method only can solve the multi-attribute decision problem that the type of the attribute value is the exact type. In reality, we often encounter the situation that the attribute value is the interval attribute value besides the attribute type of the fuzzy and rough model. In college physical education evaluation, we always encounter the interval data. This paper introduces the risk factors and the precise interval data before using the TOPSIS method. Therefore, we propose a multi-attribute decision method based on the Grey and TOPSIS method. And we combine the Euclid distance with the Grey correlation degree as a standard for judging the advantages and the disadvantages for a scheme. Then we apply this method to the evaluation system of the college physical education teaching. According to the computer simulation this method shows a good performance. 


\section{The Research of TOPSIS}

\subsection{The Traditional Steps for the TOPSIS Method}

Assuming the scheme sets of the multi-attribute problem is $A=\left\{A_{1}, A_{2}, \cdots, A_{m}\right\}$. The attribute sets is $F=\left\{f_{1}, f_{2}, \cdots, f_{n}\right\}$. The decision matrix is $B=\left\{b_{i j}\right\}_{m \times n}$. Among them, $b_{i j}$ is the attribute value of the $j$ attribute in the scheme $i, i=1,2, \cdots, m, j=1,2, \cdots, n$. The scheme $A_{i}$ is written as $A_{i}=\left(b_{i 1}, b_{i 2}, \cdots, b_{i n}\right), i=1,2, \cdots, m, b_{i j} \geq 0$. The weight vector of the attribute is $W=\left(\omega_{1}, \omega_{2}, \cdots, \omega\right)^{T}$. Among them, $\sum_{j=1}^{n} \omega_{j}=1, \omega_{j} \geq 0, j=1,2, \cdots, n$. The traditional TOPSIS method can deal with the problem for the multi-attribute decision. And the basic steps are as follows.

The first step is to construct the standardized decision matrix $C=\left(c_{i j}\right)_{m}$ by asing the vector standardized method. For the benefit attribute,

For the cost attribute,

$$
c_{i j}=\frac{b_{i j}}{\sqrt{\sum_{i=1}^{m} b_{i j}{ }^{2}}}
$$

Where $i=1,2, \cdots, m, j=2, n, n$.

The second step to construct the veighted standardization decision matrix $Z=\left(z_{i j}\right)_{m \times n}$. Where $z_{i j}=\omega_{i j} c_{i j},=1, \cdots, m, j, 1, \cdots, n$.

The third step is to determine the positive ideal solution $A^{+}$and the negative ideal solution $A^{-}$. Then defining two antificial scheme. The positive ideal scheme and the negative ideal scheme are $A^{+}=\left(z_{1}^{+}, z^{+},-\right)$and $A^{-}=\left(z_{1}^{-}, z_{2}^{-}, \cdots, z_{n}^{-}\right)$. They express as the most preference scheme and the least preference scheme. For the benefit attribute, $z_{j}^{+}=\max _{i} z_{i j}, z_{j}^{-}=\min z_{i j}$. For the cost attribute, $=\min _{i} z_{i j}, z_{j}^{-}=\max _{i} z_{i j}$.

The fourth step is to calculate the Eculid distance $d_{i}^{+}$and $d_{i}^{-} \cdot d_{i}^{+}$is the distance from each scheme to the positive ideal solution. And $d_{i}^{-}$is the distance from each scheme to the negative-ideal solution.

$$
\begin{aligned}
& d_{i}^{+}=\left\|\mathrm{z}_{i}-A^{+}\right\|=\sqrt{\sum_{j=1}^{n}\left(z_{i j}-z_{j}^{+}\right)^{2}} \\
& d_{i}^{-}=\left\|\mathrm{z}_{i}-A^{-}\right\|=\sqrt{\sum_{j=1}^{n}\left(z_{i j}-z_{j}^{-}\right)^{2}}
\end{aligned}
$$

Where $i=1,2, \cdots, m, j=1,2, \cdots, n, z_{i}=\left(z_{i 1}, z_{i 2}, \cdots, z_{i n}\right)$. 
The fifth step is to calculate the relative degree $C_{i}^{+}$for each scheme and the positive ideal solution.

$$
C_{i}^{+}=\frac{d_{i}^{-}}{d_{i}^{+}+d_{i}^{-}}
$$

Where $i=1,2, \cdots, m$.

It can be seen if $z_{i}=A^{+}, C_{i}^{+}=1$. And if $z_{i}=A^{-}, C_{i}^{+}=0.0 \leq C_{i}^{+} \leq 1$. When $C_{i}^{+} \rightarrow 1$ the scheme $A_{i} \rightarrow A^{+}$.

The sixth step is to prioritize each scheme according to the descending order for $C_{i}^{+}$.

\subsection{The Analysis of the TOPSIS Problems}

In order to illustrate the problems which TOPSIS exist, this paper gives anexample of a simple multi-attribute decision.

One core enterprise needs to select a partner from three candidate suppliers. The related data of each candidate supplier are as Table 3.2.

Table 3.2. The Data of the Suppliers

\begin{tabular}{c|c|c}
\hline Attribute & The quality of the product & \multicolumn{2}{c}{ Theprice of the product/yuan } \\
\hline Supplier a & 0.9 & 8 \\
\hline Supplier b & 0.8 & 7 \\
\hline Supplier c & 05 & 11 \\
\hline Supplier d & 0.58 & 8.6 \\
\hline Supplier e & 0.6 & 8.5 \\
\hline
\end{tabular}

Among them, the two attribute weights are 0.5 and 0.5 .

Then the original decision matrix of the multi-attribute decision problem is as follows.

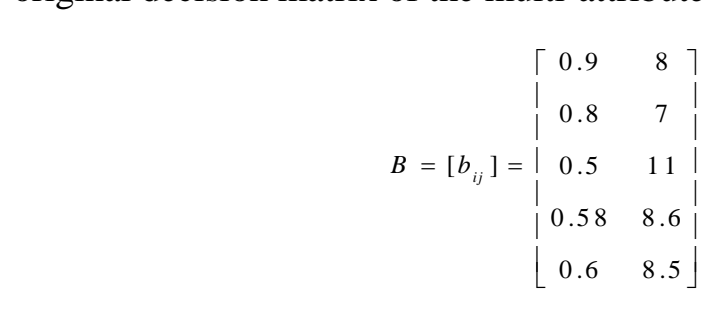

The first step is to construct the standardized decision matrix by adopting the range transformation method.

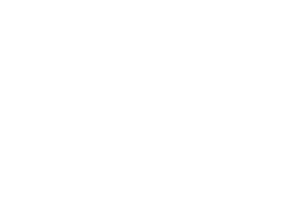

$$
C=\left(c_{i j}\right)_{5 \times 2}=\left[\begin{array}{cc}
1 & 0.75 \\
0.75 & 1 \\
0 & 0 \\
0.2 & 0.8 \\
0.5 & 0.2
\end{array}\right]
$$

The second step is to construct the weighted normalized decision matrix $Z=\left(z_{i j}\right)_{m \times n}$.

Among them, $z_{i j}=0.5 c_{i j}$. 


$$
Z=\left(z_{i j}\right)_{5 \times 2}=\left[\begin{array}{cc}
0.5 & 0.375 \\
0.375 & 0.5 \\
0 & 0 \\
0.1 & 0.4 \\
0.25 & 0.25
\end{array}\right]
$$

The third step is to determine the positive ideal solution $A^{+}$and the negative ideal solution $A^{-}$. Defining the two artificial schemes. That is, the positive ideal scheme and the negative ideal scheme.

$$
A^{+}=(0.5,0.5), A^{-}=(0,0)
$$

They represent the most preference scheme and the least preference scheme.

The fourth step is to calculate the Euclid distance $d_{i}^{+}$and $d_{i}^{-} \cdot d_{i}^{+}$is the distance from each scheme to the positive ideal solution. And $d_{i}^{-}$is the distance from each scheme to the negative ideal solution.

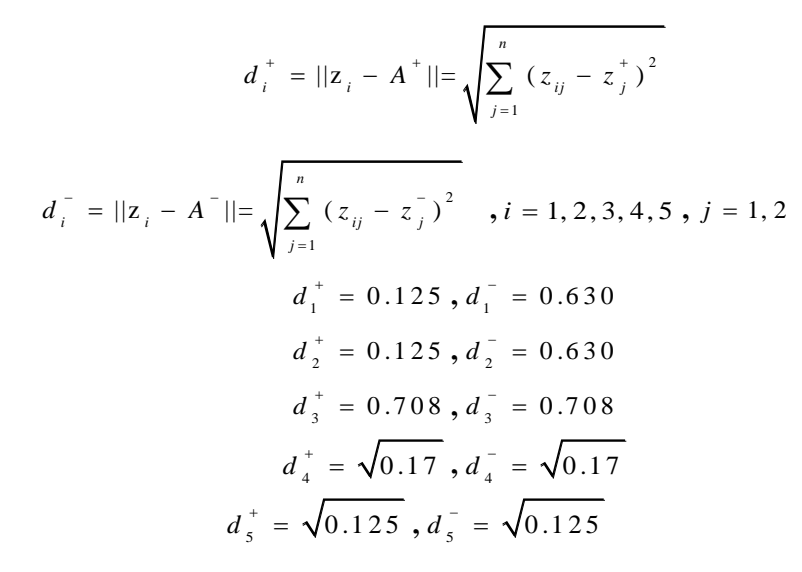

The fifth step is to compute the relatiye degree between each scheme and the positive ideal solution $C_{i}^{+}$.

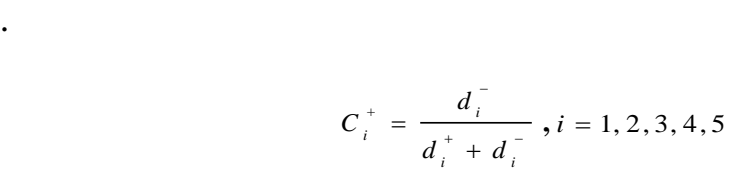

Then

$$
C_{1}^{+}=C_{2}^{+}=0.84, C_{3}^{+}=0, C_{4}^{+}=C_{5}^{+}=0.5
$$

The sixth step is to prioritize for the scheme according to the descending order $C_{i}^{+}$.

We can see that the scheme $a$ is the same to the scheme $b$ and the scheme $d$ is the same to the scheme e. Therefore, we could not get the unique best scheme. That is to say, using the tradiunal TOPSIS method cannot distinguish the advantages and the disadvantages between the scheme a and the scheme b. Similarly, the scheme $d$ and the scheme e cannot distinguish. 


\section{Grey-TOPSIS Method}

\subsection{The Basic Steps for the Grey Relational Analysis}

The basic steps for the Grey relational analysis in the multi-attribute decision problem are as follows.

The first step is to collect, analyze the original data and construct the Grey correlation sets. The reference data sequence (the mother sequence) is written as $a^{(0)}=\left(a_{1}^{(0)}, a_{2}^{(0)}, a_{3}^{(0)}, \cdots, a_{n}^{(0)}\right)$.

The compared data sequence (the subsequence) is recorded as $a^{(i)}=\left(a_{1}^{(i)}, a_{2}^{(i)}, a_{3}^{(i)}, \cdots, a_{n}^{(i)}\right)$.

The second step is to preprocess the original data and get the standardized data.

$$
\begin{aligned}
x^{(0)}= & \left(x_{1}^{(0)}, x_{2}^{(0)}, x_{3}^{(0)}, \cdots, x_{n}^{(0)}\right) \\
& \cdots \cdots \cdots \cdots \cdots \cdots \cdots \cdots \cdots \\
x^{(i)} & =\left(x_{1}^{(i)}, x_{2}^{(i)}, x_{3}^{(i)}, \cdots, x_{n}^{(i)}\right)
\end{aligned}
$$

The third step is to calculate the Grey correlation coefficien matrix for each scheme and the original scheme.

Where,

$$
r_{i j}=\frac{\min _{i} \min _{j}\left|x_{0 j}-x_{i j}\right|+\varepsilon \max _{j} \max _{j}\left|x_{0}\right|}{\left|x_{0 j}-x_{i j}\right|+\varepsilon \max _{j}\left|x_{0} \bigodot x_{i j}\right|}
$$

Where, $\varepsilon \in(0,1)$ is the distinguishing coefficient. And the general value is 0.5 .

The fourth step is to ensure the degree of the Grey incidence $r_{i}^{*}$. That is, calculating the arithmetic mean value $r_{i}^{*}=\frac{1}{n} \sum_{j=1}^{n} r_{i j}$ for the correlation coefficient.

The fifth step is to relevancy rank. That is, we rank each scheme according to the correlation results.

\subsection{The Multi-attribute Grey-TOPSIS Method}

The TOPSIS method can reflect the proximity for the scheme and the original scheme from the distance of the position. The Grey correlation method can reflect the proximity for the scheme and the-idea scheme from the shape similarity. This paper combines the two aspects to construct a new method in order to determine the advantages and the disadvantages for the scheme.

$A=\left\{A_{1}, A_{2}, \cdots, A_{\text {is }}\right.$ is the scheme sets for the multi-attribute problem. $F=\left\{f_{1}, f_{2}, \cdots, f_{n}\right\}$ is the attribute sets for the multi-attribute problem. The decision matrix is $X=\left(x_{i j}\right)_{m \times n}$. Among them, $x_{i j}$ S the attribute value of the $j$ attribute in the scheme $i, i=1,2, \cdots, m, j=1,2, \cdots, n$. The weighted vector is $\omega=\left(\omega_{1}, \omega_{2}, \cdots, \omega\right)^{T}$ satisfying $\sum_{j=1}^{n} \omega_{j}=1 . i=1,2, \cdots, m, j=1,2, \cdots, n$.

The specific steps are as follows.

The first step is to standardize the original decision matrix $X=\left(x_{i j}\right)_{m \times n}$. Then getting $Y=\left(y_{i j}\right)_{m \times n}$.

For the benefit attribute

$$
y_{i j}=\frac{x_{i j}-\min _{i} x_{i j}}{\max x_{i j}-\min x_{i j}}
$$


For the cost attribute

$$
y_{i j}=\frac{\max _{i} x_{i j}-x_{i j}}{\max _{i} x_{i j}-\min _{i} x_{i j}}
$$

Where, $i=1,2, \cdots, m, j=1,2, \cdots, n$.

The second step is to calculate the weighted normalization decision matrix $Z=\left(z_{i j}\right)_{m \times n}$. Where, $i=1,2, \cdots, m, j=1,2, \cdots, n$.

The third step is to determine the positive ideal solution $Z^{+}$and the positive ideal solution $Z^{-}$for the weighted normalization decision matrix.

$Z^{+}=\left(z_{1}^{+}, z_{2}^{+}, \cdots z_{n}^{+}\right)=\omega, Z^{-}=\left(z_{1}^{-}, z_{2}^{-}, \cdots z_{n}^{-}\right)=0$.

Where, $z_{j}^{+}=\max z_{i j}=\omega_{j}, z_{j}^{-}=\min z_{i j}=0, i=1,2, \cdots, m, j=1,2, \cdots, n$.

The fourth step is to calculate the Eculid distance $d_{i}^{+}$and $d_{i}^{-}$.

$i=1,2, \cdots, m, j=1,2, \cdots, n$.

$$
\begin{aligned}
& d_{i}^{+}=\left\|z_{i}-A^{+}\right\|=\sqrt{\sum_{j=1}^{n}\left(z_{i j}-z_{j}^{+}\right)^{2}} \\
& d_{i}^{-}=\left\|z_{i}-A^{-}\right\|=\sqrt{\sum_{j=1}^{n}\left(z_{i j}-z\right)}
\end{aligned}
$$

The fifth step is to calculate the Grey, correlation coefficient matrix $R^{+}$and $R^{-}$for each scheme to the positive ideal solution and the negative ideal solution.

Where,

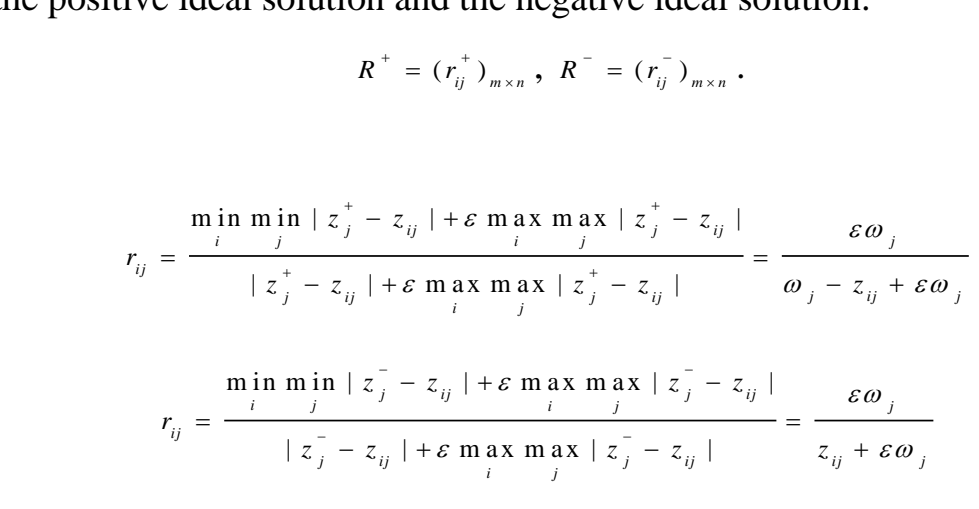

Where, $\varepsilon \in(0,1)$ is the distinguishing coefficient, and the general value is 0.5 .

The sixth is to the Grey correlation degree $r^{+}$and $r^{-}$or each scheme to the positive ideal solution and the negative ideal solution.

$$
r_{i}^{+}=\frac{1}{n} \sum_{j=1}^{n} r_{i j}^{+}, r_{i}^{-}=\frac{1}{n} \sum_{j=1}^{n} r_{i j}^{-} .
$$

The seventh step is to handle dimensionless processing for the distance $d_{i}^{+}, d_{i}^{-}$and the correlation degree $r^{+}, r^{-}$.

$$
\begin{gathered}
D_{i}^{+}=\frac{d_{i}^{+}}{\max _{i} d_{i}^{+}}, D_{i}^{-}=\frac{d_{i}^{-}}{\max _{i} d_{i}^{-}}, \\
R^{+}=\frac{r_{i}^{+}}{\max _{i} r_{i}^{+}}, R^{-}=\frac{r_{i}^{-}}{\max _{i} r_{i}^{-}}, i=1,2, \cdots, m
\end{gathered}
$$


The eighth step is to calculate the relative closeness degree $T_{i}^{+}=\frac{D_{i}^{-}}{D_{i}^{+}+D_{i}^{-}}$and $S_{i}^{+}=\frac{R_{i}^{+}}{R_{i}^{+}+R_{i}^{-}}$.

The values of $T_{i}^{+}$and $S_{i}^{+}$are bigger, the scheme is closer to the positive ideal solution.

The ninth step is to merge $T_{i}^{+}$and $S_{i}^{+}$. Then ensuring the weight $v_{1}$ and $v_{2} \cdot Q_{i}^{+}=v_{1} T_{i}^{+}+v_{2} S_{i}^{+}$. Among them, $v_{1}$ and $v_{2}$ reflect the preference degree of the position and the shape for the decision makers. $v_{1}+v_{2}=1, v_{1}=v_{2}=\frac{1}{2}$.

The tenth step is to rank for the schemes according to $Q_{i}^{+}$.

$s$ and $t$ reflect the preference degree of the position and the shape for the decision makers. Therefore, when encountering the traditional TOPSIS problem which points out 3.5 , we only need to use the method to solve. Because this method introduces the Grey correlation method based on the traditional TOPSIS method. That is, it considers not only the proximity of the decision position but also the shape similarity. When meeting the two rankings are the same, we only need to change the value $s$ and $t$ appropriately. Then the problem can be solved easily.

\section{Computer Simulation}

We operate the college P.E. teaching evalation system by computer simulation. We evaluate the P.E. teaching level for 7 universities from 5 aspects. They are content of courses, teaching method, sports test, and extracurricular sports activities and training and otherwise. The indexes are shown as below:

Table 2. Spoits Evaluation System

\begin{tabular}{|c|c|c|}
\hline Index & Category & Weight \\
\hline & l Education $A_{1}$ & $55 \% \omega_{A 1}$ \\
\hline & Teaching Management $A_{2}$ & $15 \% \omega_{A 2}$ \\
\hline & Equipment $A_{3}$ & $30 \% \omega_{A 3}$ \\
\hline \multirow{5}{*}{ Sports Test $C$} & Teaching Mode $B_{1}$ & $50 \% \omega_{B 1}$ \\
\hline & Teaching Means $B_{2}$ & $50 \% \omega_{B 2}$ \\
\hline & Award $C_{1}$ & $10 \% \omega_{C 1}$ \\
\hline & Learning and Exercise Ability for Students $C$ & $50 \% \omega_{c 2}$ \\
\hline & $\begin{array}{l}\text { Scientific Research and Competition Ability } \\
\qquad \mathrm{C}_{3}\end{array}$ & $40 \% \omega_{C 3}$ \\
\hline \multirow{2}{*}{$\begin{array}{c}\text { Extracurricular Sports } \\
\text { Activities and Training } \\
\qquad D\end{array}$} & Extracurricular Sports Activities $D_{1}$ & $60 \% \omega_{D 1}$ \\
\hline & Extracurricular Sports Training $D_{2}$ & $40 \% \omega_{D 2}$ \\
\hline \multirow[b]{2}{*}{ Otherwise $E$} & Teaching Style $E_{1}$ & $60 \% \omega_{E 1}$ \\
\hline & $\begin{array}{l}\text { Communication between Teachers and } \\
\text { Students } E_{2}\end{array}$ & $40 \% \omega_{E 1}$ \\
\hline
\end{tabular}


The score $A$ is $A_{1} \cdot \omega_{A 1}+A_{2} \cdot \omega_{A 2}+A_{3} \cdot \omega_{A 3}$.

The score $B$ is $B_{1} \cdot \omega_{B 1}+B_{2} \cdot \omega_{B 2}$.

The score $C$ is $C_{1} \cdot \omega_{C 1}+A_{2} \cdot \omega_{C 2}+A_{3} \cdot \omega_{C 3}$.

The score $D$ is $D_{1} \cdot \omega_{D 1}+D_{2} \cdot \omega_{D 2}$.

The score $E$ is $E_{1} \cdot \omega_{E 1}+E_{2} \cdot \omega_{E 2}$.

There are 7 universities. Namely multiple attribute decision making scheme set $U=\left\{U_{1}, U_{2}, U_{3}, U_{4}, U_{5}, U_{6}, U_{7}\right\}$.

The weight of the attribute is $\omega=\{0.15,0.2,0.2,0.3,0.15\}$. The score table is shown as

Table 3. The Score of Each University

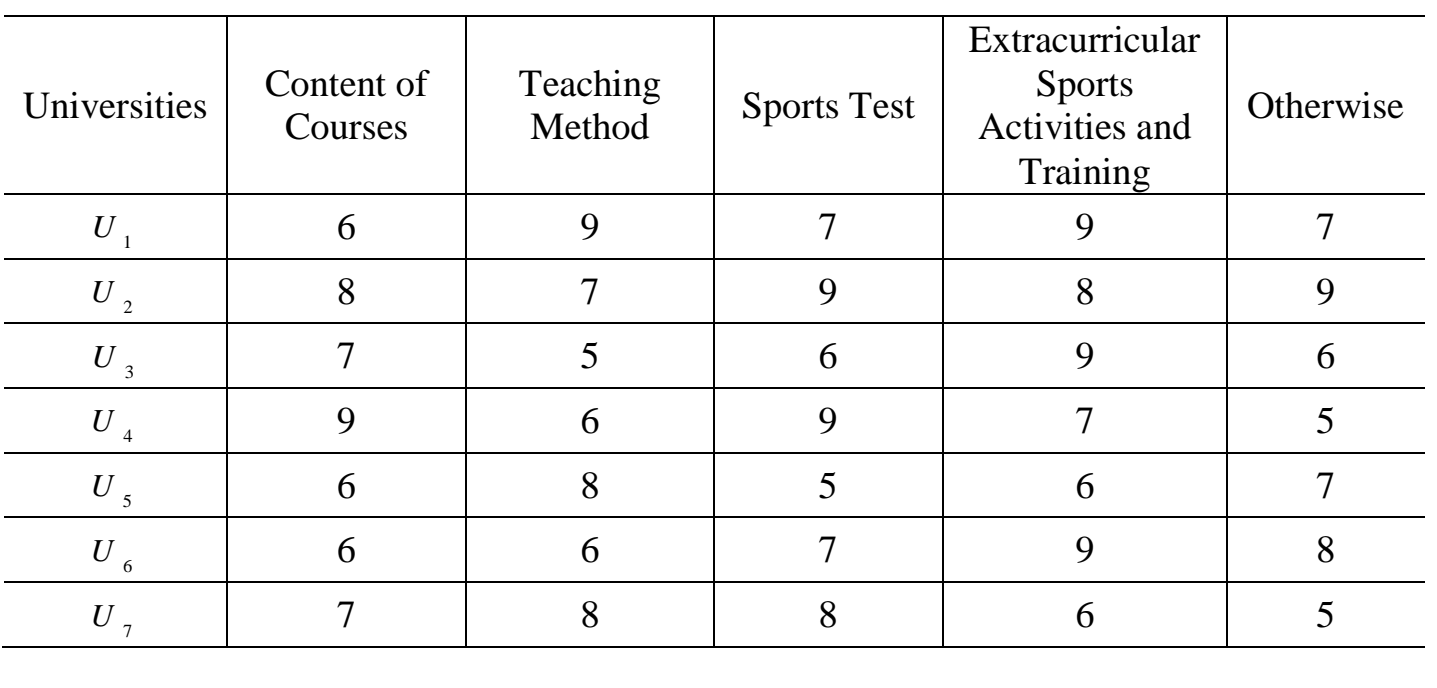

Firstly, we normalize the matrix and get the weighting matrix.

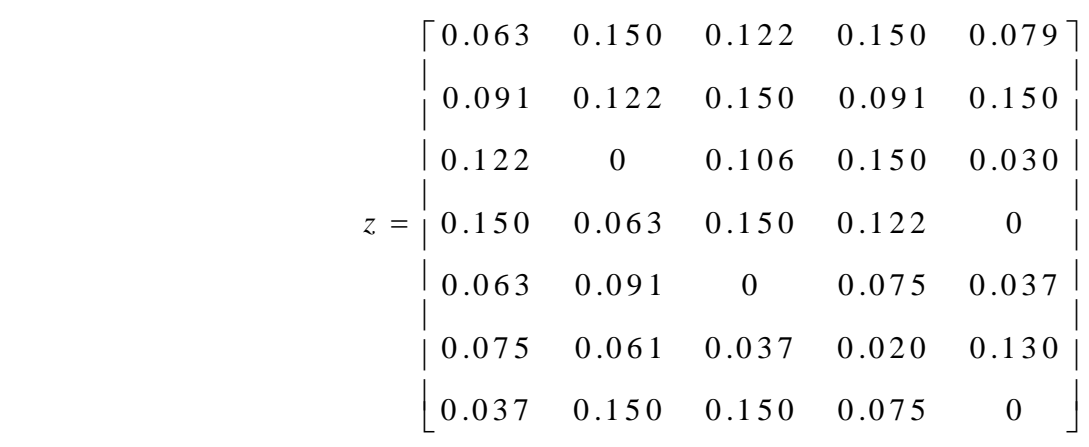

Secondly, we confirm the positive deal solution and the negative ideal solution in weighted normalized matrix.

$$
\begin{gathered}
Z^{+}=[0.15,0.2,0.2,0.3,0.15] \\
Z^{-}=[0,0,0,0,0]
\end{gathered}
$$


Thirdly, we compute the Euclid distance among each scheme and the positive ideal solution. Then, we compute the Euclid distance among each scheme and the negative ideal solution.

$$
\begin{aligned}
& d^{+}=(0.316,0.157,0.061,0.341,0.176,0.324,0.183) \\
& d^{-}=(0.224,0.331,0.397,0.120,0.280,0.187,0.296)
\end{aligned}
$$

Fourthly, we calculate the grey relational degree among each scheme and the positive ideal solution. Then, we calculate the grey relational degree among each scheme and the negative ideal solution.

$$
\begin{aligned}
& r^{+}=(0.771,0.798,0.912,0.630,0.812,0.763,0.878) \\
& r^{-}=(0.863,0.732,0.679,0.918,0.711,0.732,0.843)
\end{aligned}
$$

Fifthly, we compute the relative closeness coefficient after nondimensionalizing the grey relational degree.

$$
\begin{aligned}
& T^{+}=(0.210,0.280,0.243,0.191,0.233,0.240,0.187 \\
& S^{+}=(0.213,0.274,0.236,0.178,0.258,0.264,0.193
\end{aligned}
$$

\begin{tabular}{|c|c|c|}
\hline Universities & Traditional TOPSIS & Grey-TOPSIS \\
\hline$U_{1}$ & 1 & 1 \\
\hline & 4 & 4 \\
\hline & 2 & 3 \\
\hline$U_{4}$ & 6 & 6 \\
\hline & 7 & 7 \\
\hline$U_{6}$ & 2 & 2 \\
\hline $\mathbb{U}_{7}$ & 5 & 5 \\
\hline
\end{tabular}

Finally, we count the $Q^{+}$with $v_{1}=v_{2}=\frac{1}{2}$

$$
Q^{+}=(0.672,0.420,0.5160314,0.257,0.543,0.358)
$$

So, the rank of the university P.E. evaluation is

$$
U_{1}>U \geqslant U_{3}>U_{2}>U_{7}>U_{4}>U_{5}
$$

Table 4. The Comparison of Two Methods

From the comparison, we can see that the order of Grey-TOPSIS is similar with the traditional TOPSIS method. And the Grey-TOPSIS method can solve the problem that the traditional TOPSIS cannot rank the schemes when the close degrees are same. Our GreyTOPSIS is effective.

\section{Conclusion}

The quality of the college physical education affects the talent training effect directly. The Development of the ordinary sports teaching evaluation is an effective way to strengthen the sports management of the ordinary colleges. And is also ensures the teaching quality of the 
college physical education. In the network construction of colleges and universities in China, the physical teaching assessment is still a vacant. Therefore, this paper completes the following works. Firstly, we improved the TOPSIS method and get a Grey-TOPSIS method which can handle the interval value. Secondly, we apply the Grey-TOPSIS to the college sports teaching evaluation and establish the evaluation system of the college physical education teaching. Thirdly, we get the university evaluation ranking and compare this method with the traditional TOPSIS.

\section{References}

[1] X. Zhang, "The application of Fuzzy Math in College P.E. Evaluation”, Sports \& Science, vol. 6, (1996), pp. 58-59.

[2] X. Mingxin, G. Xin, L. I. Ruinian and J. U. Chuanjin, "Study on Meta-evaluation Applied to the Evaluatiôn Practice of University Physical Education”, Journal of Qingdao University, vol. 13, no. 4, (2002), pp. 74-79.

[3] L. Dong, "On the Function of Universities' P.E. Evaluation", Journal of Haerbing Physical Education Institute, vol. 3, no. 22, (2004), pp. 15-15.

[4] C. L. Hwang and K. P. Yoon, "Multiple attributes decision making: Methods and applications", New York: Springer-Verlag, (1981).

[5] L. Chen and H. M. Sun, "The competitiveness evaluation of Chinese provincial high-tech industry", Science and Technology Management Research, vol. 5, no. 2, (2011), pp. 76-79.

[6] I. Chamodrakas, N. Alexopoulou and D. Martakos, "Customer evaluation for order acceptance using a novel class of fuzzy method based on TOPSIS", Expert Systems with Applications vol. 36, no. 4, (2009), pp. 7409-7415.

[7] T. Kaya and C. Kahraman, "Multicriteria decision making in ênergy planning using a modified fuzzy TOPSIS methodology”, Expert Systems with Applications, vol. 38, no 6, (2011), pp. 6577-6585.

[8] G. Torlak, M. Sevkli, M. Sanal and S. Zaim, Analyzing basiness competition by using fuzzy TOPSIS method: An example of Turkish domestic ailine industry", Expert Systems with Applications, vol. 38, no. 4, (2011), pp. 3396-3406.

[9] M. Behzadian, S. K. Otaghsara, M. Yazdani and J. Ignatius, "A state-of the-artsurvey of TOPSIS applications. Expert Systems with Applications", vol.39 no. 17, (2012), pp. 13051-13069.

[10] D. Kahneman, and A. Tversky, "Prospect theory An analysis of decision under risk", Econometrica, vol. 47, (1979), pp. 263-291.

[11] L. F. A. M. Gomes and M. M.P. P Lima, "TODIM: Basics and application tomulticriteria ranking of projects with environmental impacts", Foundations of Computing and Decision Sciences, vol. 16, no. 3-4, (1992), pp. $113-127$.

[12] X. Wentao and R. Huan, "A extended TOPSIS method for the stochastic multi-criteria decision making problem through interval estimation , $2^{\text {nd }}$ International workshop on intelligent systems and applications (ISA) (2010), pp. 1-4.

[13] C. T. Chen, "Extensions of the TOPSIS for group decision-making under fuzzy environment", Fuzzy Sets and Systems, vol. 114 , (2000), pp. 1-9.

[14] R. A. Krohling and Y. C. Campanharo, "Fuzzy TOPSIS for group decision making: A case study for accidents with oil spl1 in the sea", Expert Systems with Applications, vol. 38, no. 4, (2011), pp. 4190-4197.

[15] G. Lee, K. S. Jun and E. S. Chung, "Robust spatial flood vulnerability assessment for river using fuzzy TOPSIS with a-cut level set", Expert Systems with Applications, vol. 41, no. 2, (2014), pp. 644-654.

[16] F. E. Boran, S.Gen, M. Kurt and D. Akay, "A multi-criteria intuitionistic fuzzy group decision making for supplier selection with TOPSIS method”, Expert Systems with Applications, vol. 36, no. 8, (2009), pp. $11363-11368$.

[17] R. A Krohling and T. T. M. de Souza, "Combining prospect theory and fuzzy numbers to multi-criteria decision making", Expert Systems with Applications, vol. 39, no. 13, (2012), pp. 11487-11493.

[18] R. A. Krohling, A. G. Pacheco and A. L. Siviero, "IF-TODIM: An intuitionistic fuzzy TODIM to multicriteria decision making”, Knowledge-Based Systems, vol. 53, (2013), pp. 142-146.

[19] R. Lourenzutti and R. A. Krohling, "A study of TODIM in a intuitionistic fuzzy and random environment", Expert Systems with Applications, vol. 40, no. 13, (2013), pp. 6459-6468.

[20] Z. P. Fan, X. Zhang, F. D. Chen and Y. Liu, "Extended TODIM method for hybrid multiple attribute decision making problems", Knowledge-Based Systems, vol. 42, (2013), pp. 40-48. 


\section{Author}

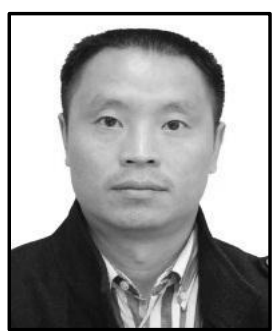

Shengtao Wu, Male, he was born in Chongqing, China in 1972. Now, he is an associate professor in Yangtze normal college sports and health sciences, and his research directions are national sports and sports sociology and humanities email.

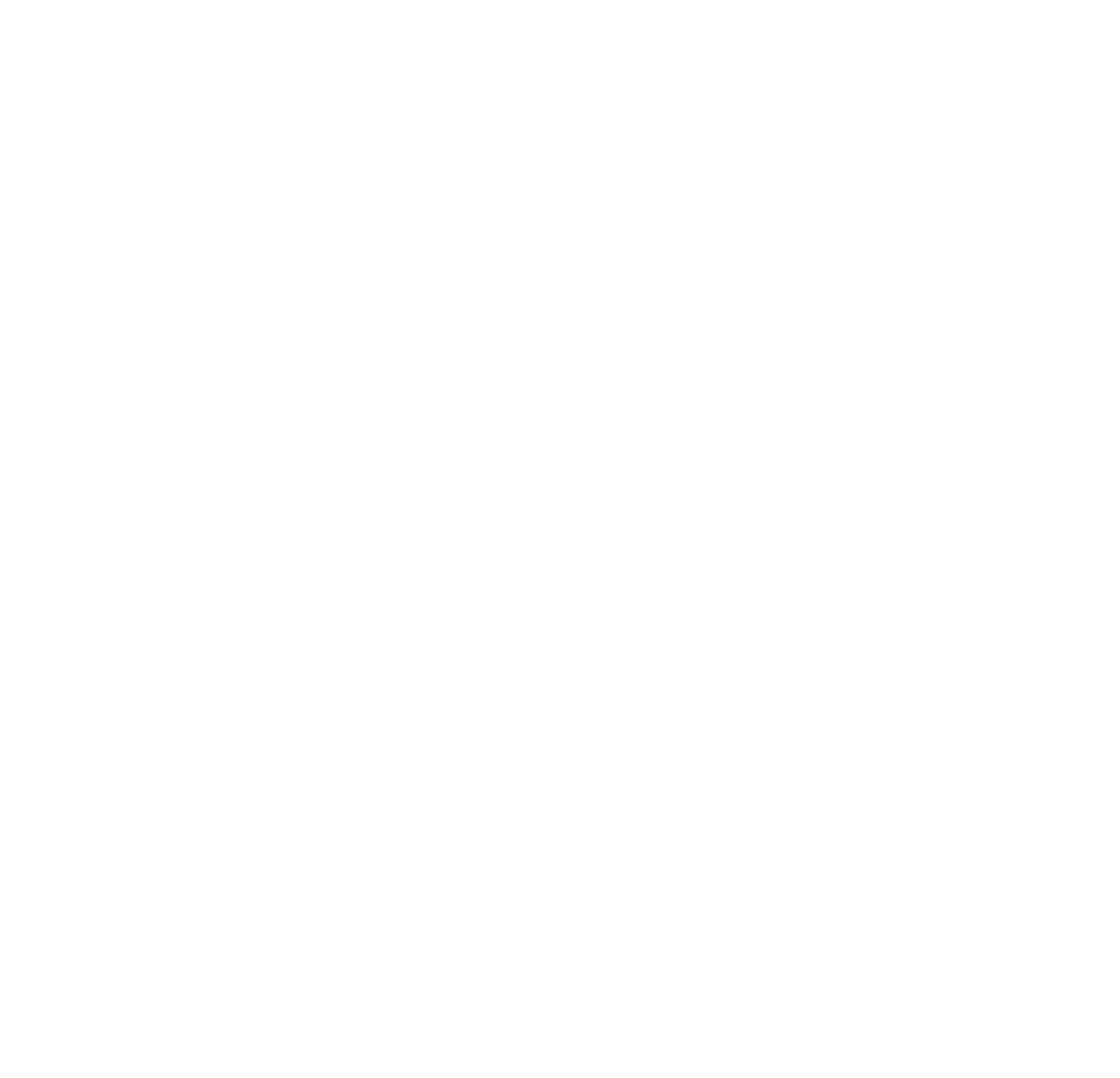

